\title{
Mental retardation
}

BEHAVIORAL PHARMACOLOGY IN MENTAL

RETARDATION

$\underline{S}$ Tuinier, WMA Verhoeven

Vincent van Gogh Institute for Psychiatry, Dept. Biological

Psychiatry, P.O. Box 5, 5800 AA Venray, The Netherlands

Hardly any of the usual psychopharmacological compounds is tested in mentally retarded populations for there respective indications. That makes psychopharmacological treatment of mentally retarded a difficult affaire. Further, the relative inadequacy of adult western psychiatric nosological categories for mentally retarded populations is an additional complicating factor. The possibility that specific psychiatric syndromes, not quite resembling the usual psychiatric syndromes, may exist in the various disorders that lead to mental retardation contributes again to the confusion, as does the fact that effect measurement instruments are relatively inadequate in the mentally retarded. However, this situation parallels that in clinical psychiatry, where psychopharmacological intervention can hardly be called "syndrome-specific". There is a growing awareness that biological factors, and as a consequence pharmacological interventions, are more related to specific behavioral and functional disturbances, than to psychiatric syndromes as a whole. Behavioral pharmacology aims at investigating the relationship between drugs and more discrete functional disturbances. The dissection of behavioral and psychiatric "syndromes" in the mentally retarded into the component parts could especially in mentally retarded patients be very worthwhile. Targetsymptoms for psychopharmacological intervention have to be sorted out in order to make progress in this field. In this presentation the behavioral pharmacological approach in mentally retarded patients will be outlined. 